\title{
Práticas avaliativas favorecedoras à aprendizagem no contexto da inclusão: a subjetividade em foco
}

\author{
Evaluative practices that favor learning in the context of inclusion: the \\ subjectivity in focus
}

\section{Prácticas evaluativas que favorecen el aprendizaje en un contexto de inclusión: la subjetividad en foco}

\author{
Bárbara da Silva Ferreira Gonçalves \\ Professora da Secretaria de Estado de Educação do Distrito Federal, Brasília, DF, Brasil \\ E-mail: goncalvesbarbarasf@gmail.com ORCID: https://orcid.org/0000-0001-8531-8103 \\ Cristina Massot Madeira-Coelho \\ Professora doutora da Universidade de Brasília, Brasília, DF, Brasil \\ E-mail: cristina.madeira.coelho@gmail.com ORCID: https://orcid.org/0000-0002-9727-5419
}

Recebido em 14 de novembro de 2020

Aprovado em 12 de julho de 2021

Publicado em 31 de agosto de 2021

\section{RESUMO}

Este artigo tem como objetivo evidenciar práticas avaliativas que favorecem a aprendizagem e o desenvolvimento do estudante com deficiência, consideradas a partir da produção subjetiva docente. Este trabalho foi organizado a partir de pesquisa mais ampla que constituiu a dissertação de mestrado da primeira autora do artigo. A pesquisa, ancorada na perspectiva cultural-histórica, teve como base os pressupostos teórico, epistemológico e metodológico da Teoria da Subjetividade de González Rey. A produção da informação foi realizada a partir de pesquisa em escola pública do Distrito Federal, em uma região considerada de periferia, e teve como participante a professora do $1^{\circ}$ ano do Ensino Fundamental I, de uma turma em que estava incluído um menino com diagnóstico de Transtorno do Espectro Autista. Realizada em 2019, a pesquisa contribuiu para ressaltar a relevância do processo avaliativo decorrente da concepção de aprendizagem como processo subjetivo que favoreceu o desenvolvimento do estudante com deficiência incluído naquela sala de aula. Evidencia-se, assim, que o processo avaliativo decorrente da concepção subjetiva da aprendizagem possibilita reconhecer e valorizar as peculiaridades do desenvolvimento de cada estudante e, dessa forma, favorece o rompimento com modelos comparativos e padronizados da avaliação tradicional.

Palavras-chave: Aprendizagem; Estudante com deficiência; Práticas avaliativas; Subjetividade docente.

\section{ABSTRACT}

This article aims to make evident evaluative practices that favor the learning and development of students with disabilities, considered from the teaching subjectivity production. This work was organized based on a broader research that constituted the 
http://dx.doi.org/10.5902/1984686X63084

master's degree dissertation of the first author of the article. The research, anchored in the cultural-historical perspective, was based on the theoretical, epistemological and methodological assumptions of González Rey's Theory of Subjectivity. The production of the information was carried out through research at a public school in the Federal District, in a region considered to be periphery, and had as a participant the teacher of the 1 st grade of Elementary School, from a class that included a boy with a diagnosis of Autism Spectrum Disorder. Held in 2019, the research contributed to make evident the relevance of the evaluation process resulting from the concept of learning as a subjective process that favored the development of students with disabilities included in that classroom. Thus, it is evident that the evaluation process resulting from the subjective conception of learning makes it possible to recognize and value the peculiarities of each student's development and, in this way, favors the break with comparative and standardized models of traditional evaluation.

Keywords: Learning; Student with disabilities; Evaluative practices; Teaching subjectivity.

\section{RESUMEN}

Este artículo tiene como objetivo resaltar las prácticas evaluativas que favorecen el aprendizaje y desarrollo de los estudiantes con deficiencia, a través de la producción subjetiva de los docentes. El trabajo se organizó a partir de una investigación más amplia sobre la tesis de maestría del primer autor del artículo. La investigación, fundamentada en la perspectiva histórico-cultural, se basó en los supuestos teóricos, epistemológicos y metodológicos de la Teoría de la Subjetividad de González Rey. La producción de la información se realizó a través de una investigación en una escuela pública del Distrito Federal, de una región considerada periférica, y tuvo como participante una profesora de 1er año de Educación Primaria, en un aula con un niño diagnosticado con Trastorno del Espectro Autista. Realizada en el 2019, la investigación contribuyó a resaltar la relevancia del proceso evaluativo, derivado de una concepción de aprendizaje como proceso subjetivo que favoreció el desarrollo del estudiante con deficiencia incluido en esa aula. Además, se evidenció que el proceso evaluativo resultante de la concepción subjetiva del aprendizaje permite reconocer y valorar las peculiaridades del desarrollo de cada alumno y, por tanto, favorece la ruptura con los modelos comparativos y estandarizados de evaluación tradicional.

Palabras clave: Aprendizaje; Estudiante con deficiencia; Prácticas evaluativas; subjetividad docente.

\section{Introdução}

As atuais discussões em torno da avaliação pedagógica apresentam a preocupação de romper com práticas tradicionais seletivas e excludentes que se baseiam em uma estrutura monocultural e se guiam, fundamentalmente, pelo instrumento prova.

No cenário brasileiro, autores como Villas Boas (2017), Hoffmann (2013), Luckesi (2005), entre outros, contribuem, dentro das particularidades de discussão de cada autor, 
http://dx.doi.org/10.5902/1984686X63084

para evidenciar a importância da dimensão processual e qualitativa da avaliação e assim romper com o paradigma tradicional.

De um modo geral, as discussões trazidas por esses autores conduzem a reflexões que compreendem a relação entre os processos de aprendizagem e de desenvolvimento como companheiros inseparáveis dos processos de avaliação.

Em que pese as contribuições dos autores citados acima, este artigo rompe com a perspectiva formativo-conceitual com que o tema vem sendo tratado no campo científicoacadêmico e aborda a temática da avaliação pedagógica a partir das produções singulares do indivíduo.

Nesse sentido, o presente artigo tem como objetivo evidenciar práticas avaliativas que favorecem a aprendizagem e o desenvolvimento do estudante com deficiência, consideradas a partir da produção subjetiva docente. Por meio da demonstração de contextos avaliativos favorecedores da aprendizagem e do desenvolvimento do estudante com deficiência, procura-se indicar a relação que a qualidade destas práticas mantém com a dimensão subjetiva do docente que as utiliza, o que contribui para compreender a complexidade do processo avaliativo.

A partir da concepção de Hoffmann (2013) de que para avaliar a aprendizagem é necessário ultrapassar leituras preconcebidas e buscar leituras multidimensionais, nos aproximamos da Teoria da Subjetividade de González Rey e colocamos em evidência a dimensão subjetiva no campo da avaliação, dialogando com a produção do conhecimento constituída até o momento.

Na perspectiva de González Rey, a dimensão subjetiva participa da constituição dos diversos processos humanos e, nesse sentido, a Teoria da Subjetividade nos possibilita evidenciar aspectos que estão envolvidos no processo avaliativo, mas que historicamente foram omitidos em razão de perspectivas normativas e positivistas.

Analisar fenômenos do cotidiano escolar, por exemplo, a avaliação pedagógica, como uma complexa teia de sentidos, marcados por produções singulares do docente, geradas no coletivo e simultaneamente na história de vida de cada um, e buscar compreender as implicações que essas produções têm no processo de avaliar, favorece pensar a relevância das produções subjetivas na organização dos processos escolares, suas formas de expressão e o processo de constituição de concepções relacionadas à aprendizagem e ao desenvolvimento do estudante com deficiência. 
http://dx.doi.org/10.5902/1984686X63084

\section{A avaliação pedagógica na literatura: o movimento das discussões e o impacto na compreensão de aprendizagem}

Na revisão da literatura, a análise do material pesquisado revelou movimento em torno da necessidade de romper com práticas tradicionais de avaliação que têm se expandido e se intensificado no cotidiano das práticas pedagógicas das escolas, como marcador da eficiência e eficácia dos sistemas de ensino, sobretudo, voltado à verificação da produtividade (SANTOS; MITJÁNS MARTÍNEZ, 2016) e seleção dos melhores (BAPTISTA; PALHANO; PEREIRA, 2017).

De um modo geral, os artigos evidenciam a concepção formativa da avaliação como processo de acolhimento e respeito, que tem como maior interesse garantir as aprendizagens. Dessa maneira, observa-se um distanciamento do enfoque classificatório e seletivo da avaliação tradicional, e uma discussão mais voltada para o caráter processual da avaliação e sua estreita relação com o planejamento pedagógico.

$\mathrm{Na}$ avaliação nós não precisamos julgar, necessitamos isto sim, de diagnosticar, tendo em vista encontrar soluções mais adequadas e mais satisfatórias para os impasses e dificuldades. Para isso, não é necessário nem ameaça, nem castigo, mas sim acolhimento e confrontação amorosa. (LUCKESI, 2005, p. 33)

Nessa perspectiva, é possível perceber que a avaliação docente assume caráter de diagnóstico (GIVIGI, et al., 2015 e MARIN; BRAUN, 2018), de descoberta (BAPTISTA; PALHANO; PEREIRA, 2017 e MELLO; HOSTINS, 2018), de reflexão (MARIN; BRAUN, 2018 NASCIMENTO, et al., 2017), de organização (GIVIGl, et al., 2015 e MELLO; HOSTINS, 2018), de construção da aprendizagem (GIVIGI, et al., 2015), de revisão (GIVIGI, et al., 2015 e MARIN; BRAUN, 2018) e de intervenção (BAPTISTA; PALHANO; PEREIRA, 2017 e MARIN; BRAUN, 2018) na prática pedagógica.

Vale destacar que os trabalhos, em sua essência, apontam para a compreensão de que a avaliação não pode encerrar nem a oportunidade de o estudante mostrar o que aprendeu, nem a possibilidade de o professor observar, intervir e modificar o planejamento e a prática pedagógica, demonstrando que no campo científico a prática de avaliar a aprendizagem foi superada e deu lugar à concepção de avaliar para a aprendizagem¹.

A concepção de avaliar para as aprendizagens aparece com força em pesquisas que envolvem a temática da educação inclusiva e da perspectiva histórico-cultural (BAPTISTA; PALHANO; PEREIRA, 2017, CUNHA; ROSSATO, 2015, MARIN; BRAUN, 2018, MORI, 2016, NASCIMENTO et al., 2017). Ambas as linhas colocam em pauta a singularidade do 
http://dx.doi.org/10.5902/1984686X63084

estudante e os mais diversos elementos que atravessam o processo educativo, provocando reflexões que impactam não só a ação avaliativa como também a própria compreensão de aprendizagem que até então estava fortemente associada a concepções instrumentalizadas de ensino.

Verifica-se, então, que a mudança no paradigma avaliativo possibilita reconhecer o estudante como sujeito ${ }^{2}$ dando visibilidade a processos singulares, históricos e culturais que participam da ação de aprender. Essa proposição abre caminhos para compreender não só a aprendizagem como produção complexa como também compreender a pessoa que aprende como ativa, reflexiva e emocional.

Deste modo, a discussão em torno da avaliação pedagógica ganha a compreensão de que avaliar para a aprendizagem consiste em reconhecer e valorizar as diferentes dimensões que atravessam o processo educativo, buscando vias alternativas favorecedoras da aprendizagem.

Por fim, os estudos citados colaboraram para compreender o movimento das discussões em torno da avaliação no processo pedagógico e os avanços no campo educacional em relação à temática, dando destaque à relevância de se compreender, por meio da concepção formativa da avaliação, as diferentes dimensões que atravessam a aprendizagem e, a partir disso, refletir ações que colaborem para tal fim. É nesse sentido que trazemos a discussão da dimensão subjetiva da aprendizagem.

\section{A dimensão subjetiva da aprendizagem: reflexões relacionadas à avaliação do estudante com deficiência no contexto da escola inclusiva}

O conceito de aprendizagem nas escolas, em sua maioria, tem se associado às capacidades cognitivas, possíveis de serem observadas de forma direta e objetiva, demonstrando uma concepção instrumentalizada de aprendizagem no qual a dimensão subjetiva não participa.

No entanto, a subjetividade, como produção qualitativamente humana "gerada na vida social como produção de caminhos simbólico-emocionais" (GONZÁLEZ REY, 2011a, p.118), constitui todos os espaços da vida social. No ambiente escolar, a dimensão subjetiva participa na ação e das relações do aprender, integra-se a outras experiências de vida e se expressa de forma complexa na aprendizagem.

A Teoria da Subjetividade, proposta por González Rey, ao salientar a dimensão subjetiva que envolve a aprendizagem avança na compreensão da complexidade que 
http://dx.doi.org/10.5902/1984686X63084

circunda e extrapola o ambiente escolar, possibilitando reflexões acerca dos diferentes aspectos que permeiam o processo de ensino-aprendizagem. De acordo com a Teoria da Subjetividade:

\begin{abstract}
A aprendizagem escolar não é um processo essencialmente individual no sentido de ser intrapsíquico, como muitas vezes é representado no senso comum, e também, no contexto escolar. A aprendizagem é um processo tanto individual como social [...]. Na aprendizagem escolar se geram sentidos subjetivos por meio das quais a história de vida de cada aprendiz integra-se ao contexto diferenciado vividos por eles na sala de aula e na escola (MITJÁNS MARTíNEZ; GONZÁLEZ REY, 2017, p. 66):
\end{abstract}

Desta forma, compreendemos, então, que a aprendizagem, mais que um processo cognitivo, é marcada pelo movimento e pelas interligações da subjetividade individual e social que geram sentidos subjetivos ${ }^{3}$ diversos e se configuram na experiência de aprender, isto é, a aprendizagem acontece como um sistema, uma rede complexa que se entrelaça, em sua dimensão simbólico-emocional, com aprendizagens atuais e anteriores de contextos diversos.

Para o processo de ensino-aprendizagem, considerar a dimensão subjetiva que envolve a aprendizagem permite não só superar a ideia de assimilação como processo essencial do ensino que prioriza o externo e sufoca qualquer tipo de produção individual, como também possibilita ao professor a investigação das necessidades do estudante, abrindo espaços singulares de intervenção que favoreçam caminhos em direção da aprendizagem. Assim, os sentidos subjetivos que participam da configuração subjetiva de aprender tornam-se fontes muito ricas e importantes tanto para a organização do processo de ensino-aprendizagem como para o favorecimento da emergência do sujeito neste processo que, nessa concepção teórica, representa "a capacidade de posicionamento de indivíduos e grupos, cujos limites estão na própria produção simbólica da cultura e nos recursos subjetivos para assumir os desafios dos espaços existenciais da experiência" (GONZÁLEZ REY; MITJÁNS MARTÍNEZ, 2017, p.73).

Em relação à aprendizagem do estudante com deficiência, a dimensão subjetiva da aprendizagem não pode ser analisada diretamente pelo transtorno ou pela deficiência, pois, os sentidos subjetivos relacionados à aprendizagem não correspondem a estados orgânicos, ou seja, não aparecem associados de modo direto, mas por meio de configurações subjetivas muito diversas, no qual o transtorno ou a deficiência é um elemento constituinte da complexa rede que envolve seu desenvolvimento. 
http://dx.doi.org/10.5902/1984686X63084

Compreender que o transtorno/deficiência não constitui uma configuração subjetiva em si possibilita considerar que o processo de ensino-aprendizagem se configure de modo a reconhecer e valorizar o caráter gerador de produções subjetivas singulares do estudante com deficiência que não são consideradas pelo modelo biomédico. No modelo biomédico, estes estudantes são vistos de forma homogênea, encaixados em um padrão de diagnóstico que determina e limita suas aprendizagens, desconsiderando qualquer possibilidade de o estudante se inscrever no processo de ensino-aprendizagem, isto é, anulando seu caráter ativo.

Para Madeira-Coelho; Oliveira e Pinto (2017) os diagnósticos e laudos, que são avaliações clínicas, não podem sobrepor-se aos sujeitos, sob pena de limitarem percursos de desenvolvimento. Para favorecer o desenvolvimento, é necessário, entre outros, observar a trama entre a produção de sentidos subjetivos presentes na ação de aprender e a subjetividade social, atravessadas pelo individual e coletivo, que singulariza cada estudante. De acordo com González Rey:

A deficiência limita certos processos sensoriais, físicos ou intelectuais, de acordo com o caso, mas em todos eles existe um caminho de desenvolvimento que permite à pessoa avanços concretos e possiblidades múltiplas em sua integração e condição social. Esse caminho de desenvolvimento acontece por recursos subjetivos [...] (GONZÁLEZ REY, 2011b, p. 66).

Ao tomar a dimensão subjetiva no processo de educação inclusiva, rompe-se com concepções que homogeneízam a aprendizagem do estudante com deficiência e se abre caminhos e possibilidades de aprendizagem e desenvolvimento negligenciados por um longo tempo no ambiente escolar em razão dos transtornos/deficiências (NUNES; SAIA; TAVARES, 2015). Se, no processo de educação inclusiva, os estudantes com deficiência fossem verdadeiramente compreendidos em sua singularidade "possivelmente livraria muitos desses alunos de rótulos estereotipados procedentes da desconsideração da forma diversa que eles têm de compreender e de se posicionar frente ao conhecimento" (TACCA; GONZÁLEZ REY, 2008, p. 145)

Assim, as categorias de sentido subjetivo e configuração subjetiva na escola inclusiva adquirem particular importância no desenvolvimento de uma prática pedagógica singularizada, que se organiza na tensão da multiplicidade de aspectos que participam da ação de aprender. Em relação à avaliação, compreender a aprendizagem como produção subjetiva implica, primeiro, pensar sobre esses conceitos e, segundo, reconhecer 0 
http://dx.doi.org/10.5902/1984686X63084

ambiente escolar, caracterizado por uma subjetividade social, como espaço favorecedor na produção de novos sentidos subjetivos.

\section{Fundamentos epistemológicos e metodológicos da pesquisa}

A metodologia de pesquisa se organizou na perspectiva da Epistemologia Qualitativa, desenvolvida por González Rey (2005), tendo como princípios gerais da produção do conhecimento: o caráter construtivo-interpretativo, a compreensão da pesquisa como um processo dialógico e a legitimação do singular como instância de produção do conhecimento científico.

$\mathrm{Na}$ instituição escolar de pesquisa, o processo de construção do cenário social possibilitou a aproximação entre a pesquisadora e a professora participante, assegurando à pesquisa, por meio do tecido relacional estabelecido, seu caráter dialógico.

Após o aceite do convite para participação na pesquisa, a professora assinou o termo de Consentimento Livre e Esclarecido recebendo, antes e no decorrer da pesquisa, todos os esclarecimentos necessários, assegurando, inclusive, o rigoroso sigilo sobre informações que permitissem identificá-la.

Conforme a metodologia construtiva-interpretativa, a escolha dos instrumentos se fez a partir do contexto dialógico que presidiu a pesquisa e, assim, foi dependente de indicadores e da construção das hipóteses formuladas ao longo do processo da pesquisa. Neste sentido, foram utilizados como principais instrumentos: 1- roda de conversa abordando a temática da avaliação e aprendizagem - como instrumento para se obter informações iniciais; 2- dinâmicas conversacionais; 3- entrevista; 4- observação nos períodos de regência e planejamento - momentos estes de construção e formulação de hipóteses e, por fim, 5- o complemento de frases como forma possível de encadear as hipóteses interpretativas já construídas.

A análise apresentada neste artigo é parte da construção-interpretativa desenvolvida no curso da pesquisa. O método construtivo-interpretativo se constitui na articulação de sistemas múltiplos de significados onde a lógica da pesquisa se converte na construção e elaboração das informações que, por meio da unidade teórico-empírica, possibilitam a construção de indicadores que sustentarão ou não as hipóteses construídas na sequência. A elaboração das hipóteses a partir dos indicadores, que reunidos e articulados às variadas informações, é que permitirá uma construção lógica configuracional no qual a pesquisa possibilitará zonas de inteligibilidade sobre o fenômeno estudado. 
http://dx.doi.org/10.5902/1984686X63084

Desta forma, a elaboração na construção de informação se deu a partir da lógica configuracional construída com base no diálogo expressivo da dinâmica dos instrumentos utilizados, no conjunto das observações realizadas, a partir de registros das gravações de áudio e do diário de campo.

\section{Construção da informação}

A professora participante da pesquisa faz parte do grupo de professores efetivos da Secretaria de Estado de Educação do Distrito Federal (SEEDF) que atua nas escolas públicas da região. No ano da pesquisa ela compunha o grupo de professoras do 1ํano do Ensino Fundamental I, matutino, na escola pesquisada e atuava em uma Classe Comum Inclusiva ${ }^{4}$ com 15 alunos onde um desses, $\mathrm{Hugo}^{5}$, apresentava diagnóstico de Transtorno do Espectro Autista (TEA).

Hugo, ficou conhecido por diferentes profissionais da escola por, nos anos anteriores, ter o hábito de ficar fora da sala de aula, pelo comportamento agressivo e pelo difícil relacionamento que mantinha com os colegas e professores. $E$, foi nesse contexto que ocorreu a pesquisa sobre o processo de avaliação com foco na dimensão subjetiva da professora Sofia 6 .

Sofia tem 40 anos de idade, é casada e tem uma filha. Atua como professora do Ensino Fundamental I desde 1998 na SEEDF, sempre em sala de aula, ora em Classe Comum, ora em Classe Comum Inclusiva.

Ao analisar o perfil profissional da participante foi possível identificar o compromisso e a exigência com que ela encara a profissão docente, aspecto que é expressado em diferentes momentos da pesquisa e está bem caracterizado nestes relatos:

Eu sempre fui desde a infância e sou até hoje e tento desconstruir um pouco isso. Eu sou muito exigente comigo mesmo. Eu sempre quero... eu não sou assim com excelência em tudo, mas eu fico buscando essa excelência em tudo o que eu vou fazer... (Trecho de Dinâmica Conversacional transcrito de gravação de áudio).

Em outro momento:

... meu foco era a não dependência financeira de ninguém, começava já pelo meu pai. Consegui isso. Maravilha, eu me realizei aí, mas por trás disso já têm tantas outras exigências dentro dessa profissão [...] que aí eu já comecei outras exigências comigo mesmo, tem que né... assim... sei lá... trabalhar com a melhor metodologia, tenho que tentar sempre tá aprendendo, tenho que tentar sempre tá me superando. Não é... e eu falo isso muito assim comigo mesmo, não é para agradar a direção, não é para agradar... É uma coisa comigo! (Trecho de Dinâmica Conversacional transcrito de gravação de áudio). 
http://dx.doi.org/10.5902/1984686X63084

Em algumas frases do complemento de frases, foi possível identificar:

Quero: contribuir para o melhor

Tentarei: ser melhor sempre

Preciso: realizar mais

Quando tenho dúvidas: fico com medo

No ambiente escolar, o compromisso e a exigência da docente aparecem na organização do trabalho pedagógico da sala de aula, na rotina, na realização das atividades e de modo muito especial na relação estabelecida com seus alunos que por muitas vezes se expressa por um olhar ou por um cruzar de braços.

A forma com que a docente resolve conflitos também expressa essas características. Certo dia Hugo se irritou e não voltou para a sala permanecendo sentado em um banco do lado de fora. Sofia ao conversar com ele diz: Você é meu aluno ou, não é? Você tá comigo ou não tá? Minha turma é comigo, se você é meu aluno eu quero você dentro da sala, se não é (meu aluno) amanhã você vem direto para esse banco.

O compromisso e a exigência, que a docente expressa em relação à sua profissão, aparecem amalgamados na compreensão de que seus objetivos enquanto professora dependem do tecido relacional professor-aluno. Para a professora a emocionalidade, como ela mesmo denomina, atravessa o processo de ensino-aprendizagem e disso depende 0 desenvolvimento do seu trabalho:

Tem horas que eu fico em cima do muro, se eu for muito dura com ele. É bom? É ruim? Quando ele está em um momento de crise dar uma postura mais rígida com ele... É bom? É ruim? Então você fica o tempo inteiro tentando acertar ... (Trecho de Dinâmica Conversacional transcrito de gravação de áudio).

Essa compreensão foi possível de ser analisada também quando, em um momento de conversa informal, Sofia relata ter ficado muito frustrada com ela mesmo em uma situação em que Hugo ficou nervoso no recreio e se recusava a entrar na sala e ela, por avaliar que já tinha tido muitos avanços em relação ao seu comportamento, tentou colocálo dentro da sala. Sofia disse que sua atitude foi na intenção de mostrar que aquele comportamento de Hugo a desagradava e que ele precisava cumprir as regras como o restante da turma, mas disse também que o olhar do estudante lançado à ela, seguido de sua fuga, a fizeram sentir medo de que esta única atitude de força desconstruísse toda a 
http://dx.doi.org/10.5902/1984686X63084

relação que havia sido estabelecida entre eles, o laço afetivo e, consequentemente, seu trabalho.

As reflexões de Sofia trazem a concepção de que "avaliar em educação significa acompanhar essas surpreendentes mudanças admirando aluno por aluno em seus jeitos especiais de viver" (Hoffmann, 2013, p. 59, grifo da autora) o que expressa também um movimento constante de autoavaliação onde as práticas são pensadas a partir do resultado de ações anteriores. Podemos observar isso pelo trecho já citado:

[...] Quando ele está em um momento de crise dar uma postura mais rígida com ele... É bom? É ruim? Então você fica o tempo inteiro tentando acertar... (Trecho de Dinâmica Conversacional transcrito de gravação de áudio).

Ou pelo complemento de frases:

$$
\begin{aligned}
& \text { Ensinar: é aprender } \\
& \text { O trabalho: é um fluxo } \\
& \text { O passado: é histórico } \\
& \text { O outro: é aprendizagem }
\end{aligned}
$$

Pelo complemento de frases citado podemos perceber também a forma como passado e presente se imbricam na maneira como Sofia subjetiva aspectos avaliativos no desenvolvimento de sua profissionalidade docente. O complemento O passado: é histórico expressa uma dimensão subjetiva de que, para Sofia, os acontecimentos passados possuem valor para o momento presente, mas que esse momento presente não está determinado pelos acontecimentos passados, já que $O$ trabalho: é um fluxo.

Essa análise ganha congruência pela forma como Sofia fala sobre os Registros de Avaliação $(\mathrm{RAV})^{7}$ de Hugo aos quais ela teve acesso antes de conhecer o estudante. Na entrevista com a pesquisadora, ela diz:

...eu não conhecia a pessoa do Hugo, a pessoa física do Hugo [...] nesse sentido o relatório me ajudou porque eu fui em coisas pontuais: ele faz isso, ele não fez. (citando o que estava escrito no RAV).

E também,

Para o próximo ano o que que é fundamental: a pessoa que pegar, eu falo isso... o profissional que pegar entender que ali não é uma caixinha pronta [...] não pode avaliar o Hugo nem pelos relatórios anteriores a mim, nem pelos meus relatórios só, porque dependendo da pessoa que ele convive ele transpõe determinadas... (Trecho da entrevista). 
http://dx.doi.org/10.5902/1984686X63084

Os indicadores relacionados à forma como a profissional subjetiva aspectos relacionados à sua experiência docente levam a pesquisadora a considerar a hipótese de que para Sofia, o compromisso com a profissão passa pela avaliação permanente dos diversos elementos que constituem o processo de ensino-aprendizagem, entre eles, a história, o envolvimento da dimensão emocional e a qualidade da relação professor-aluno que por sua vez regulam o desenvolvimento de sua prática. A construção dessa hipótese possibilitou destacar que as práticas avaliativas favorecedoras à aprendizagem e ao desenvolvimento do estudante com NEE se estabelecem para Sofia a partir de três configurações subjetivas predominantes em suas práticas pedagógicas, a saber:

1) A compreensão dos processos avaliativos anteriores como expressões de momentos singulares e históricos.

Ao compreender os processos avaliativos anteriores como expressões de momentos singulares e históricos, observamos que Sofia abre novos espaços de subjetivação que rompem com o ceticismo em relação às possibilidades de mudança e transformação relacionadas ao processo de ensino-aprendizagem do estudante com deficiência que se fundamentam em uma lógica educacional patologizante e biomédica.

De acordo com Mitjáns Martinez e González Rey (2017, p. 130) a descrença em relação às possibilidades de aprendizagem do estudante com deficiência "tem na sua base, entre outros fatores, a concepção da deficiência como um processo natural, inerente à criança". Contudo, observamos que a prática da professora Sofia, de buscar entender a constituição cultural e histórica que permeia os processos avaliativos, favorece a compreensão dos diversos elementos que participam da configuração do processo de ensino-aprendizagem o que abre possibilidades de mudanças para o modo de compreender o desenvolvimento e a aprendizagem do estudante com deficiência que, assim, deixa de estar marcado por concepções deterministas características da cultura do ambiente escolar.

Nesse sentido, as ações de Sofia chamam a atenção para a necessidade de uma compreensão histórico-cultural dos processos educacionais no qual as relações sociais têm forte impacto no desenvolvimento desses processos evidenciando, dessa forma, a complexidade e as contradições que entrelaçam toda uma teia de elementos que constituem o ambiente escolar e o processo educativo.

2) Seu envolvimento pessoal com a avaliação da implicação emocional do estudante nas atividades, assistida pela qualidade do tecido relacional professor-aluno. 
A prática de avaliar a implicação emocional como forma de alcançar os objetivos revela o caráter qualitativo e interativo da avaliação (MITJÁNS MARTÍNEZ; GONZÁLEZ REY, 2017) que possibilitam acompanhar a forma com que o estudante se posiciona frente à aprendizagem escolar e os possíveis impactos dessa produção simbólico-emocional ao longo do processo de ensino-aprendizagem.

Apoiada na construção de um espaço dialógico, a professora Sofia busca entender os funcionamentos operacionais que caracterizam a aprendizagem da criança, ao mesmo tempo em que também busca compreender os aspectos emocionais envolvidos neste processo. Desta maneira, a docente organiza a prática pedagógica apoiando-se nas expressões singulares dos estudantes e na relação estabelecida de modo a favorecer caminhos de subjetivação e a emergência do estudante como sujeito de seu processo de aprender.

O que se pode perceber é que, ao avaliar a implicação emocional do estudante, Sofia compreende que diferentes dimensões constituem a aprendizagem rompendo desta forma com a concepção instrumental da avaliação tradicional. Para Sofia, avaliar a implicação emocional do estudante é princípio básico de sua prática docente e isso aparece, constantemente, conduzindo e regulando o desenvolvimento do processo de ensinoaprendizagem relacionado ao estudante com deficiência.

3) O valor que a prática avaliativa tem para a compreensão da adequação de sua ação docente ou necessária reformulação da mesma.

Em diferentes momentos, pôde-se perceber a docente avaliando o resultado de sua ação e elaborando hipóteses que pudessem contribuir e favorecer ao processo de ensinoaprendizagem.

Para Sofia, o exercício de avaliar o resultado de sua ação expressa a preocupação da profissional em identificar aspectos relevantes para a organização e planejamento pedagógico a partir da singularidade e das formas de funcionamento do estudante.

Deste modo, o caráter processual e construtivo-interpretativo da avaliação (MITJÁNS MARTÍNEZ; GONZÁLEZ REY, 2017) colocam Sofia em posição de investigação pois, ainda que não os reconheça como tal, ela busca indicadores no contexto pedagógico que possibilitem sua compreensão sobre as expressões do estudante frente às práticas docente, evidenciando a necessidade do acompanhamento sistemático do processo de ensino-aprendizagem baseado em uma constante autocrítica e redirecionamentos. 
http://dx.doi.org/10.5902/1984686X63084

A autoavaliação docente aparece então como um dos elementos constitutivos para a aprendizagem pois, favorece reflexões acerca das práticas empregadas buscando estratégias que visam a superação de possíveis barreiras para a aprendizagem.

\section{Considerações finais}

É importante destacar que a atual discussão em torno do processo de avaliação pedagógica remete à compreensão de que a mesma está em função de acompanhar para intervir, como necessário, na construção do conhecimento sobres os processos vivenciados ao longo da relação pedagógica estabelecida. Desta forma, entendemos que o debate não se restringe ao campo formativo-conceitual, mas o transcende no intuito de fortalecer 0 (re)conhecimento do sujeito e suas formas de aprender.

Nesse sentido, evidencia-se a necessidade de ampliar e discutir aspectos relacionados à avaliação pedagógica para além de questões conceituais ou de questões relacionadas aos recursos avaliativos utilizados durante a avaliação docente.

O presente estudo expressa o valor que a subjetividade tem para a discussão dos aspectos relacionados à avaliação pedagógica do estudante com deficiência e abre espaço para compreender como os aspectos subjetivos participam dos processos escolares vivenciados no contexto da sala de aula da professora Sofia.

Nessa perspectiva, o estudo não pretendeu produzir receitas comportamentais ou instrumentais sobre processos avaliativos, mas indicar, em uma elaboração teórica, princípios que sustentem o fluxo contínuo de avaliações pedagógicas presentes no cotidiano educacional escolar.

A compreensão da aprendizagem em sua dimensão subjetiva e o impacto disso no processo de avaliação apresentam um conjunto de reflexões sobre a relevância dos aspectos subjetivos e a necessidade de considerá-los no ambiente escolar redimensionando a organização do trabalho pedagógico para as singularidades.

As práticas avaliativas evidenciadas como favorecedoras à aprendizagem e ao desenvolvimento do estudante com deficiência mostram que, o processo avaliativo decorrente da concepção subjetiva da aprendizagem possibilita reconhecer e valorizar as peculiaridades do desenvolvimento de cada estudante favorecendo romper com modelos comparativos e padronizados da avaliação tradicional ao resgatar as emoções, a história individual e os valores simbólicos do indivíduo, isto é, ao resgatar a dimensão singular para o planejamento e para o desenvolvimento da prática docente. 
http://dx.doi.org/10.5902/1984686X63084

Observamos assim que, buscar compreender sentidos subjetivos constantemente gerados no processo de ensino-aprendizagem contribui para pensar a elaboração de ações e estratégias que favoreçam a aprendizagem e o desenvolvimento de estudantes com deficiência o que converge com as atuais discussões em torno da concepção formativa de avaliação pedagógica.

\section{Referências}

BAPTISTA, Maria das Graças de Almeida; PALHANO, Tânia Rodrigues; PEREIRA, Aline dos Santos. Avaliação da aprendizagem e inclusão escolar: um processo de exclusão ou um ato de amor. Revista on line de Política e Gestão Educacional, v.21, n. esp.2, p. 1335-1352, nov. 2017.

CUNHA, Roseane; ROSSATO, Maristela. A singularidade dos estudantes com deficiência intelectual frente ao modelo homogeneizado da escola: reflexões sobre o processo de inclusão. Revista Educação Especial, v. 28, n. 53, p. 649-664, set./dez. 2015.

GIVIGI, Rosana Carla do Nascimento. et al. A avaliação da aprendizagem e o uso dos recursos de tecnologia assistiva em alunos com deficiências. Educação: Teoria e Prática, Rio Claro, Vol. 25, n.48, p. 150-167, jan./abr. 2015.

GONZÁLEZ REY, Fernando. Pesquisa qualitativa e subjetividade: os processos de construção da informação / Fernando González Rey; [tradução Marcel Aristides Ferrada Silva] - São Paulo: Cengage Learning, 2005.

GONZÁLEZ REY, Fernando. Subjetividade e saúde: superando a clínica da patologia. - São Paulo: Cortez, 2011a. - (Coleção construindo o compromisso social da psicologia / coordenadora Ana Mercês Bahia Bock).

GONZÁLEZ REY, Fernando. Os aspectos subjetivos no desenvolvimento de crianças com necessidades especiais: além dos limites concretos do defeito. In: MITIJÁNS MARTÍNEZ, Albertina; TACCA, Maria Carmen Vilela Rosa. Possibilidades de aprendizagem: ações pedagógicas para alunos com dificuldade e deficiência. Campinas, SP: Alínea, 2011b. p. 47-70.

GONZÁLEZ REY, Fernando; MITJÁNS MARTíNEZ, Albertina. Subjetividade: teoria, epistemologia e método. Campinas: Alínea, 2017.

HOFFMANN, Jussara. Avaliar: respeitar primeiro, educar depois. - 4 ed. - Porto Alegre: Mediação, 2013.

LUCKESI, Cipriano Carlos. Avaliação da aprendizagem na escola: reelaborando conceitos e recriando a prática. $2^{\circ} \mathrm{ed}$. Salvador: Malabares: 2005. 
MADEIRA-COELHO, Cristina Massot; OLIVEIRA, Luciana da Silva; PINTO, Karina Panizza. A intervenção pedagógica investigativa e coordenada com o sujeito que aprende: um estudo de caso. In: TACCA, M. C. (org.). A Pesquisa como Suporte da Formação e Ação Docente. Campinas: Alínea, 2017. p. 143-160.

MARIN, Márcia; BRAUN, Patrícia. Avaliação da aprendizagem em contextos de inclusão. Revista Educação Especial, Santa Maria, v. 31, n. 63, p. 1009-1024, out./dez. 2018.

MELLO, Alessandra de Fátima Giacomet; HOSTINS, Regina Célia Linhares. Construção mediada e colaborativa de instrumentos de avaliação da aprendizagem na escola inclusiva. Revista Educação Especial, v. 31, n. 63, p. 1025-1038, out./dez. 2018.

MITJÁNS MARTÍNEZ, Albertina; GONZÁLEZ REY, Fernando. Psicologia, educação e aprendizagem escolar: avançando na contribuição da leitura cultural-histórica. - São Paulo: Cortez, 2017.

MORI, Nerli Nonato Ribeiro. Psicologia e educação inclusiva: ensino, aprendizagem e desenvolvimento de alunos com transtornos. Acta Scientiarum. Education, Maringá, v. 38, n. 1, p. 51-59, jan./mar. 2016.

NASCIMENTO, Romária de Menezes. et al. Avaliação da aprendizagem do aluno com deficiência na perspectiva da inclusão escolar. Revista on line de Política e Gestão Educacional, v.21, n. esp.2, p. 1316-1334, nov. 2017.

NUNES, Sylvia da Silveira; SAIA, Ana Lucia; TAVARES, Rosana Elizete. Educação Inclusiva: Entre a História, os Preconceitos, a Escola e a Família. Psicol. ciênc. prof. [online], vol.35, n.4, pp.1106-1119, 2015.

SANTOS, Geandra Cláudia Silva.; MITJÁNS MARTINEZ, Albertina. A Subjetividade Social da Escola e os Desafios da Inclusão de Alunos com Desenvolvimento Atípico. Rev. bras. educ. espec. [online], vol.22, n.2, pp.253-268, 2016.

TACCA, Maria Carmen Vilela Rosa; GONZÁLEZ REY, Fernando. Produção de sentido subjetivo: As Singularidades dos Alunos no Processo de Aprender. Psicol. ciênc. prof., Brasília, vol. 28, n. 1, pp. 138-161, mar. 2008.

VILLAS BOAS, Benigna Maria de Freitas. Avaliação: interações com o trabalho pedagógico. - Campinas, SP: Papirus, 2017.

\section{Notas}

\footnotetext{
${ }^{1}$ A avaliação para as aprendizagens, diferente da avaliação da aprendizagem por ter característica processual geradora de ação, não se resume a ver e registrar o que se viu. Sua finalidade é auxiliar o início, o meio e o fim do sistema de ensino -aprendizagem a partir da tomada de consciência e do planejamento de ações que favoreçam o progresso do estudante. Sobre isso ver Villas Boas (2017).

${ }^{2}$ A palavra sujeito neste trabalho corresponde a um conceito da Teoria da Subjetividade que "representa aquele que abre uma via própria de subjetivação, que transcende o espaço social normativo dentro do qual suas experiencias acontecem, exercendo opções criativas no decorrer delas, que podem ou não se expressar na ação" (GONZÁLEZ REY; MITJÁNS MARTÍNEZ, 2017, p.73)
} 
3 "Os sentidos subjetivos são unidades simbólico-emocionais, nas quais o simbólico se torna emocional desde sua própria gênese, assim como as emoções vêm a ser simbólicas [...]" (González Rey, F. L; Mitjáns Martínez, 2017, p.73).

${ }^{4}$ Conforme documentos da SEEDF, a Classe Comum Inclusiva é constituída por estudantes de Classe Comum (sem deficiência) e estudantes com deficiências ou com transtornos funcionais conforme modulação para cada etapa de ensino.

${ }^{5}$ Nome fictício

${ }^{6}$ Nome fictício

7 O Registro de Avaliação é um documento da SEEDF, feito pelo professor ao final de cada bimestre. O documento de avaliação tem orientações que visam evidenciar a aprendizagem e o desenvolvimento do estudante, contudo sua redação é livre. International (CC BY-NC 4.0) 